\title{
Myosporidium merluccius n. g., n. sp. Infecting Muscle of Commercial Hake (Merluccius sp.) from Fisheries near Namibia
}

\author{
ENRIQUE BAQUERO, ${ }^{\mathrm{a}}$ MANUEL RUBIO, ${ }^{\mathrm{b}}$ IACI N. S. MOURA, ${ }^{\mathrm{c}}$ NORMAN J. PIENIAZEK ${ }^{\mathrm{c}}$ and RAFAEL JORDANA ${ }^{\mathrm{a}}$ \\ ${ }^{a}$ Department of Zoology and Ecology, University of Navarra, P. O. Box 177 31080-Pamplona, Navarra, Spain, and \\ ${ }^{\mathrm{b}}$ Department of Microbiology, University of Navarra, P. O. Box 177 31080-Pamplona, Navarra, Spain, and \\ ${ }^{\mathrm{c}}$ Division of Parasitic Diseases, National Center for Infectious Diseases, Center for Disease Control and Prevention, Atlanta, Georgia, USA
}

\begin{abstract}
A new species of Microsporidia classified to a new genus was observed in the trunk muscle of commercial hake (Merluccius capensis/paradoxus complex) from Namibian fisheries. Macroscopic examination revealed thin and dark filaments inserted among muscle fibers. Inside the filaments were many sporophorous vesicles with about 30-50 spores per vesicle. The shape of the spore was pyriform and the extruded polar filament was of moderate length (up to $4.29 \mu \mathrm{m}, \mathrm{n}=12$ ). This new species of Microsporidia is described using macrophotography, microphotography, staining, and transmission electron microscopy (TEM), as well as molecular methods. Its 16S rRNA was found to be similar to that of Microsporidium prosopium Kent et al., 1999, while both sequences were quite different from 16S rRNA sequences known for other Microsporidia. Nevertheless, this new species is separated morphologically from $M$. prosopium by the presence of 11-12 anisofilar coils and the formation of the xenoma at the site of infection. Type species
\end{abstract}

Key Words. 16S rRNA, commercial fish parasite, molecular taxonomy, Myosporidium merluccius n. sp. n. g., spore morphology.

$\mathrm{S}$ PECIES of the Phylum Microsporidia (Balbiani, 1882) have been reported from many fish species (Canning and Lom 1986; Dyková 1995; Lom and Dyková 1992; Lom and Nilsen 2003; Shaw and Kent 1999). Most of them were found to infect muscle of commercial fishes in aquaria, fish farms, and also in fishes from other sources. These infections have a detrimental effect on the production, quality, and safety of human food sources (Canning 2001). We observed microsporidia in the muscle of commercial hake (Merluccius capensis/paradoxus complex) from Namibia in fillets submitted for evaluation by a concerned fish vendor. After a literature search and by using various tools to describe the parasite, we conclude that it is a new species belonging to a new genus as shown by morphological as well as by molecular analysis. This is the first report of microsporidia in the muscle of hake (Merluccius sp.).

\section{MATERIALS AND METHODS}

Four fillets of commercial hake (Merluccius capensis/paradoxus complex), frozen at $-30{ }^{\circ} \mathrm{C}$, were sent to our laboratory with a request to determine the nature of some black, thin filaments clearly visible in its muscle. After thawing small pieces of the fillets, 28 filaments were extracted and isolated. These filaments were stored in fish physiological saline solution $(0.9 \%)$ until further processing. Some of the fillets were preserved in $70 \%$ ethanol or were stored frozen at $-30{ }^{\circ} \mathrm{C}$ for molecular and ultrastructural investigations.

Optical microscopy. Smears of squashed filaments were wet mounted or were fixed in methanol and stained by the Giemsa stain for examination under a light microscope. Pieces of the infected muscle were embedded in paraffin, sectioned, and stained with methylene blue, hematoxylin-eosin, and periodic acid Schiff (PAS) prior to observation.

Electron microscopy. Samples for electron microscopy were fixed with $4 \%(\mathrm{v} / \mathrm{v})$ glutaraldehyde in $0.1 \mathrm{M}$ cacodylate buffer $(\mathrm{pH}$ 7.3) for $8 \mathrm{~h}$. Tissues were maintained for $24 \mathrm{~h}$ in a $0.25 \mathrm{M}$ sucrose buffer containing $0.1 \mathrm{M}$ cacodylate and post-fixed in $1 \%(\mathrm{w} / \mathrm{v})$ osmium tetroxide in phosphate buffer $(\mathrm{pH} 7.4)$ for $2.5 \mathrm{~h}$, dehydrated in ethanol, and embedded in Epon resin. Epon embedding was done in six stages: (i) $10 \%(\mathrm{v} / \mathrm{v})$ Epon $+90 \%(\mathrm{v} / \mathrm{v})$ propylene oxide for $18 \mathrm{~h}$; (ii) $25 \%(\mathrm{v} / \mathrm{v})$ Epon $+75 \%(\mathrm{v} / \mathrm{v})$ propylene oxide for $9 \mathrm{~h}$; (iii) $50 \%(\mathrm{v} / \mathrm{v})$ Epon and 50\% (v/v) propylene oxide for

Corresponding Author: E. Baquero, Department of Zoology and Ecology, University of Navarra, P. O. Box 177 31080-Pamplona, Navarra, Spain-Telephone number: +34-948-425-600; FAX number: +34-948-425-649; e-mail: ebaquero@unav.es
$15 \mathrm{~h}$; (iv) $75 \%(\mathrm{v} / \mathrm{v})$ Epon $+25 \%(\mathrm{v} / \mathrm{v})$ propylene oxide for $5 \mathrm{~h}$; (v) $90 \%(\mathrm{v} / \mathrm{v})$ Epon $+10 \%(\mathrm{v} / \mathrm{v})$ propylene oxide for $4 \mathrm{~h}$; and (vi) $100 \%$ Epon. The resin was then polymerized in an oven with the temperature slowly increasing from ambient temperature to $60^{\circ} \mathrm{C}$ within $48 \mathrm{~h}$ to overcome difficulties in fixation: first raising the temperature from ambient to $37^{\circ} \mathrm{C}$ in $1 \mathrm{~h}$, followed by incubation at $37^{\circ} \mathrm{C}$ for $15 \mathrm{~h}$; next raising the temperature from $37^{\circ} \mathrm{C}$ to $45^{\circ} \mathrm{C}$ in $1 \mathrm{~h}$, followed by incubation at $45^{\circ} \mathrm{C}$ for $15 \mathrm{~h}$; and finally raising the temperature from $45^{\circ} \mathrm{C}$ to $60^{\circ} \mathrm{C}$ in $1 \mathrm{~h}$, followed by incubation at $60{ }^{\circ} \mathrm{C}$ for $15 \mathrm{~h}$. Semi-thin tissue sections were stained with toluidine blue and evaluated by light microscopy. Selected ultra-thin sections were observed using a Zeiss EM-10 CA transmission electron microscope.

DNA extraction, amplification, and sequencing. Small samples of filaments were placed in $70 \%$ ethanol in Sarstedt 2-ml tubes (Cat. No. 72.694.006) and sent to Atlanta with ice packs (to prevent expansion of ethanol). DNA was extracted using the FastPrep method (da Silva et al. 1999). The region coding for the $16 \mathrm{~S}$ rRNA was amplified using a generic microsporidian forward PCR primer MICROF ( $3^{\prime}$-CACCAGGTTGATTCTGCCTGA-5') and a custom reverse PCR primer 1492N_9 (3'-CTACAGCTACCT TGTTACGACTT- $5^{\prime}$ ) based on the 16S rRNA sequence of Glugea atherinae, U15987. The PCR reactions contained 20 pmol of each primer per 50- $\mu 1$ reaction volume. Cycling conditions, customized for the AmpliTaq Gold PCR Master Mix (Applied Biosystems, Foster City, CA), consisted of: polymerase activation for $10 \mathrm{~min}$ at $95^{\circ} \mathrm{C}$, followed by 45 cycles of denaturation for $30 \mathrm{~s}$ at $95^{\circ} \mathrm{C}$, annealing for $30 \mathrm{~s}$ at $65^{\circ} \mathrm{C}$, and extension for $90 \mathrm{~s}$ at $72^{\circ} \mathrm{C}$. Final extension was done at $72^{\circ} \mathrm{C}$ for $9 \mathrm{~min}$, followed by a hold step at $4{ }^{\circ} \mathrm{C}$. The amplification products were purified using the StrataPrep DNA Purification Kit (Stratagene, La Jolla, CA).

Both strands of the PCR products were sequenced by using the same primers that were used for amplification and a set of custom internal sequencing primers. Sequencing reactions were done with the ABI PRISM BigDye Terminator Cycle Sequencing Kit (Applied Biosystems) and reactions were analyzed on the ABI 3100 automatic DNA sequencer (Applied Biosystems). The resulting sequences were assembled using the SeqMan II program (DNASTAR, Inc., Madison, WI) and GeneStudio Pro (Suwanee, GA). The consensus sequence for the 16S rRNA gene obtained for two independently amplified and sequenced products was assigned GenBank Accession number AY530532.

Phylogenetic analysis. Selection of microsporidian species for phylogenetic analysis was done in order to provide an easy comparison with the results of Kent et al. (1999). Small subunit ribosomal rRNA sequences of Amblyospora connecticus (GenBank Accession number AF025685), Ameson michaelis 
(L15741), Ichthyosporidium sp. (L39110), Microsporidium prosopium (AF151529), Spraguea lophii (AF033197), and Vavraia oncoperae (X74112) were retrieved from the GenBank database (http://www.pubmed.gov) and aligned with the 16S rRNA sequence of Myosporidium merluccius n. g., n. sp. by using the CLUSTAL W program version 1.83 (Thompson, Higgins, and Gibson 1994) built into the GeneStudio Pro (Suwanee, GA) molecular biology program suite. Phylogenetic analysis was performed by using the TREE-PUZZLE program v. 5.2 (Strimmer and von Haeseler 1996) and the phylogenetic trees were displayed by using the program TreeView v. 1.6.6 (Page 1996) interfaced through the GeneStudio Pro program. The tree was oriented by using the 16S rRNA sequence of Amblyospora connecticus as the outgroup.

\section{RESULTS}

The morphology of Myosporidium merluccius n. g., n. sp. Macroscopic examination of the trunk muscle of commercial hake (Merluccius capensis/paradoxus complex) revealed thin and dark filaments inserted in the muscle fibers (Fig. 1-3). The tissue did not show signs of damage or myositis. Filaments $(3-7 \mathrm{~mm}$ in length $\times 0.07-0.15 \mathrm{~mm}$ in thickness) followed the direction of the muscular fibers, and were not inside the connective tissue between the muscular fibers. These filaments were dissected under a stereoscopic microscope and wet mounts were made by squashing and smearing. They appeared to be packed with spherical vesicles, each filled with structures identified as microsporidian spores. Spores were ovoid to pyriform in shape (Fig. 4), possibly depending on the maturity of the spore. Under the microscope, extrusion of polar filaments (Fig. 5, 6) could be seen, indicating that spores maintained their infective capacity even after weeks of storage at $-30{ }^{\circ} \mathrm{C}$. Staining with Giemsa following methanol fixation presented a much clearer view of the polar filaments (Fig. 7). These observations clearly indicated that the filaments contained microsporidian spores.

Analysis of the stained slides prepared from paraffin-embedded muscle tissue revealed that these black filaments (Fig. 3) were an envelope, xenoma or a similar structure (Fig. 8, 9), which surrounds hundreds of sporophorous vesicles (Fig. 11, 12). The vesicles were embedded in a matrix of amorphous substance (Fig. 14, $15)$ in a symmetrical or asymmetrical way in the xenoma

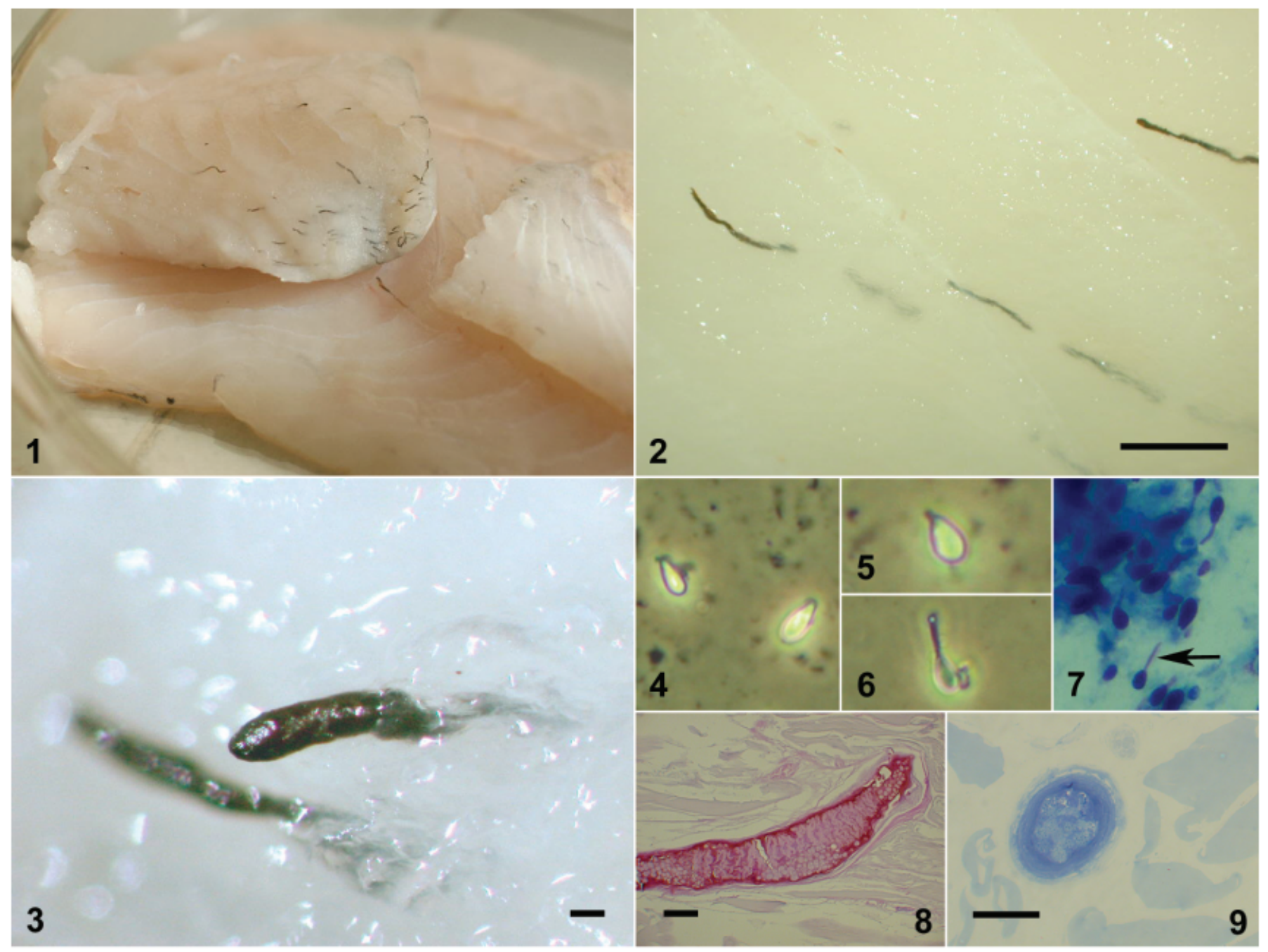

Fig. 1-9. Light micrographs of the microsporidian Myosporidium merluccius n. g., n. sp. 1. Macrophotograph of commercial hake fillets infected with black-appearing filaments of Myosporidium merluccius n. g., n. sp. 2-3. Close-up of the parasite filaments. 4-6. In vivo spores in a smear showing the polar tube extrusion. 7. Giemsa-stained smear. 8. Longitudinal section of PAS-stained filament. 9. Cross-section of toluidine blue-stained filament. (Scale bars: Fig. $2=5 \mathrm{~mm}$; Fig. 3, 8, $9=0.1 \mathrm{~mm}$.) 


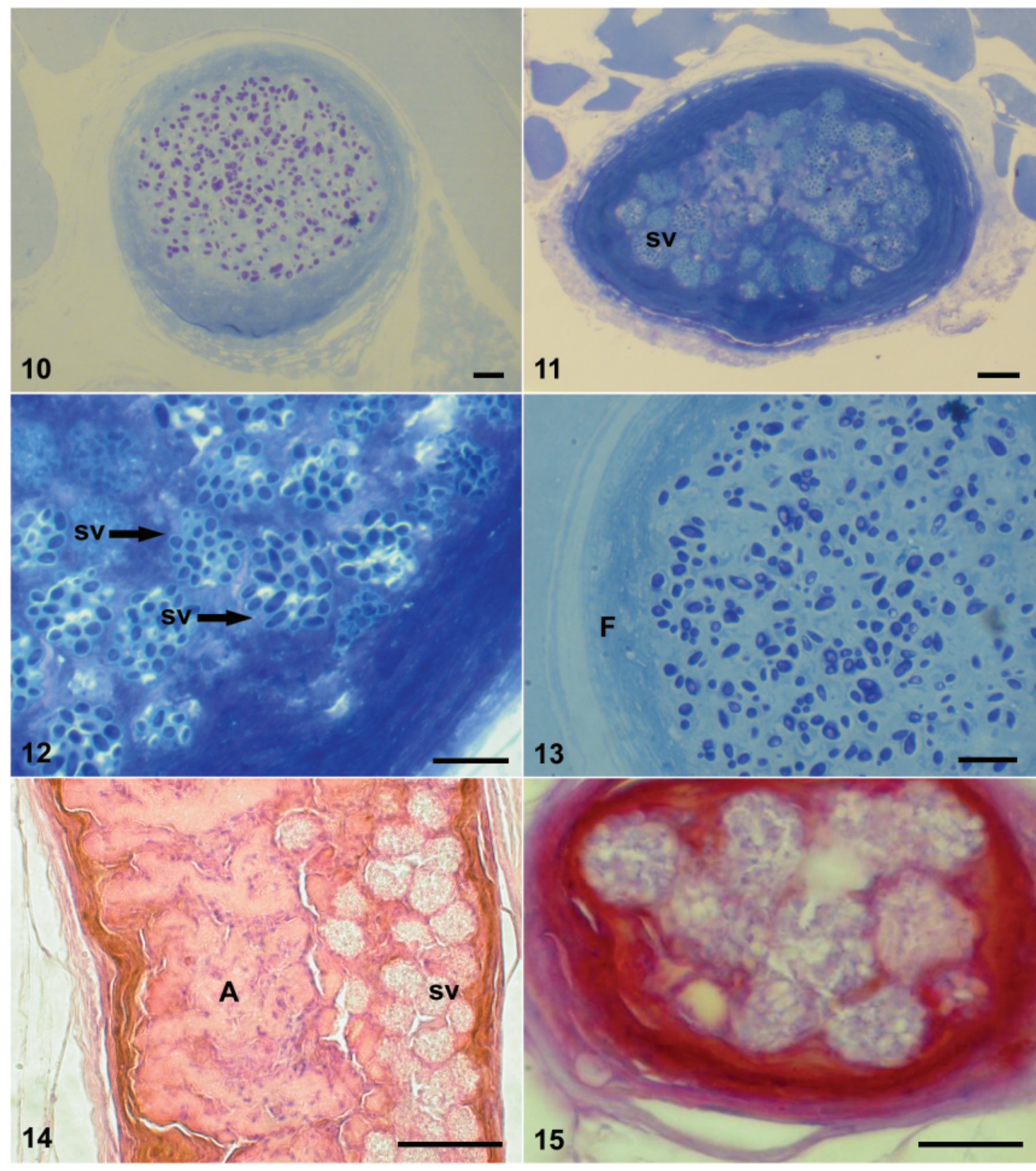

Fig. 10-15. Myosporidium merluccius n. g., n. sp. 10. Cross-section of an immature xenoma, stained with toluidine blue. 11. Cross-section of a mature xenoma, stained with toluidine blue. SV = sporophorous vesicle. 12. Part of a mature xenoma showing the sporophorous vesicle full of mature spores. SV $=$ sporophorous vesicle. 13. Cross-section of an immature xenoma, stained with toluidine blue. $\mathrm{F}=$ layers of fibroblasts. 14. Longitudinal section of a mature xenoma H\&E stained. A, amorphous material; SV, sporophorous vesicle. 15. Cross-section of a mature xenoma showing the sporophorous vesicles, H\&E stained. (Scale bars: Fig. 10, 12, $13=10 \mu \mathrm{m}$; Fig. $11,15=20 \mu \mathrm{m}$; Fig. $14=50 \mu \mathrm{m}$.) 
(centered or off-centered in the xenoma tube) as can be seen on longitudinal and transverse sections (Fig. 8, 9). Each sporophorous vesicle contained $30-50$ spores $2.5-3.3 \mu \mathrm{m}$ in length $\times 1.76$ $2.1 \mu \mathrm{m}$ in width. These vesicles could be seen clearly in the semithin sections stained with toluidine blue (Fig. 11, 12).

The wall of the spores was not penetrated by osmium and was "white" under TEM. Furthermore, we suspect that the chemistry of the spore wall was the reason that fixation had to be done for a second time for 1 wk to avoid damaging the spores during sectioning. Such damage can be observed in Fig. 5 of Kent et al. (1999) and in our Fig. 24.

Xenoma. Two kinds of xenoma-like structures were found in the infected tissue. The first kind has a rather poorly defined structure (Fig. 10, 13). Pyriform sporoblasts were visible, but sporophorous vesicles were not visible at low magnification. When the fine structure of xenomas was analyzed by TEM, this first type appeared as a mass of membranes between the sporonts and sporoblasts (Fig. 16-19). A group of both sporonts and sporoblasts was surrounded by a membrane that forms the sporophorous vesicle. In the sporoblasts, dense bodies were visible (Fig. 1618). These bodies appeared first like a twisted arc followed by the increase in the number and the size of the disks (Fig. 18, arrow). The anchoring disk was clearly visible in this phase (Fig. 19).
The second kind of xenoma contained numerous mature spores packed in well-delimited sporophorous vesicles (Fig. 11, 12, 14, $15,20,21)$. Under TEM, the spores had an irregular shape. The polar tubes were of the anisofilar type (i.e. they had two different diameters, see inset in Fig. 22) with 6-7 wide coils and 5 narrow coils (Fig. 12, 23).

We observed an envelope of fibroblasts that surrounded and gave form to the filaments visible in the fresh fish muscle (Fig. 1-3). This multilayer of fibroblasts had a thickness that increased from 7 to $20 \mu \mathrm{m}$ with xenoma maturation (Fig. 24, 25). Clearly, this is a xenoma, very frequently seen in infections of fish by microsporidia (Lom and Nilsen 2003) and defined by Vávra and Larsson (1999) as " a structure externally covered by a multilayered coat into which fibroblasts and epithelial fragments are incorporated.',

Molecular results. The length of the complete $16 \mathrm{~S}$ rRNA coding region for this new microsporidian species was 1,351 nucleotides. There were two ambiguities $(\mathrm{C}$ or $\mathrm{T})$ at positions 170 and 756 in the consensus sequence obtained from two independently amplified and sequenced samples. The composition of this molecule was $48.3 \%$ GC and it showed $99.03 \%$ similarity with the $16 \mathrm{~S}$ rRNA coding region of Microsporidium prosopium (GenBank Accession number AF151529) (Kent et al. 1999).

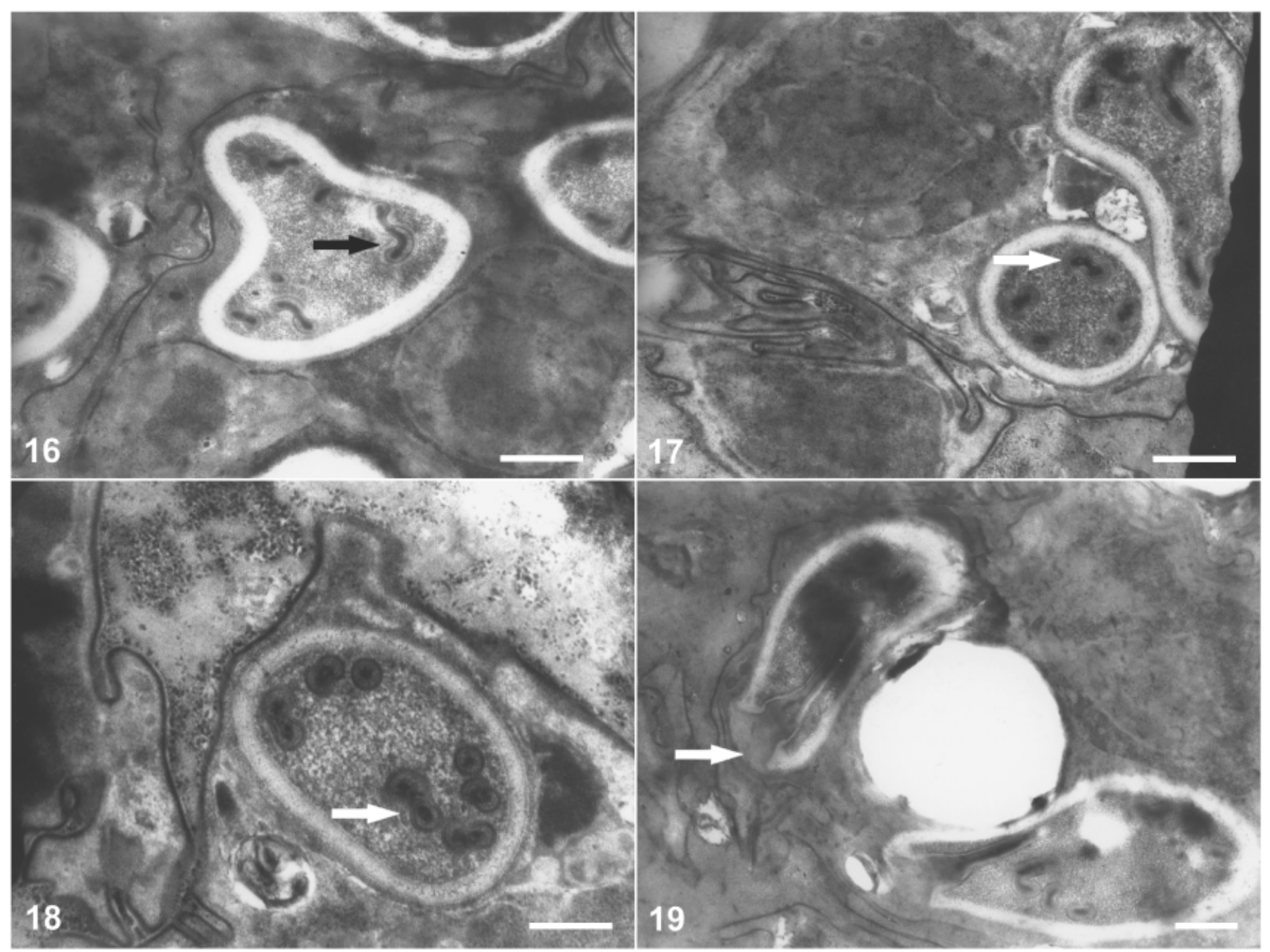

Fig. 16-19. Transmission electron micrographs of sporonts and immature spores of Myosporidium merluccius $\mathrm{n}$. g., n. sp. 16-18. Maturation process with the coils under division. The arrow indicates the dense bodies of developing polar filaments. 19. Polar disc (arrow) in immature spores. (Scale bars: Fig. $16,17,19=0.5 \mu \mathrm{m}$; Fig. $18=0.25 \mu \mathrm{m}$.) 


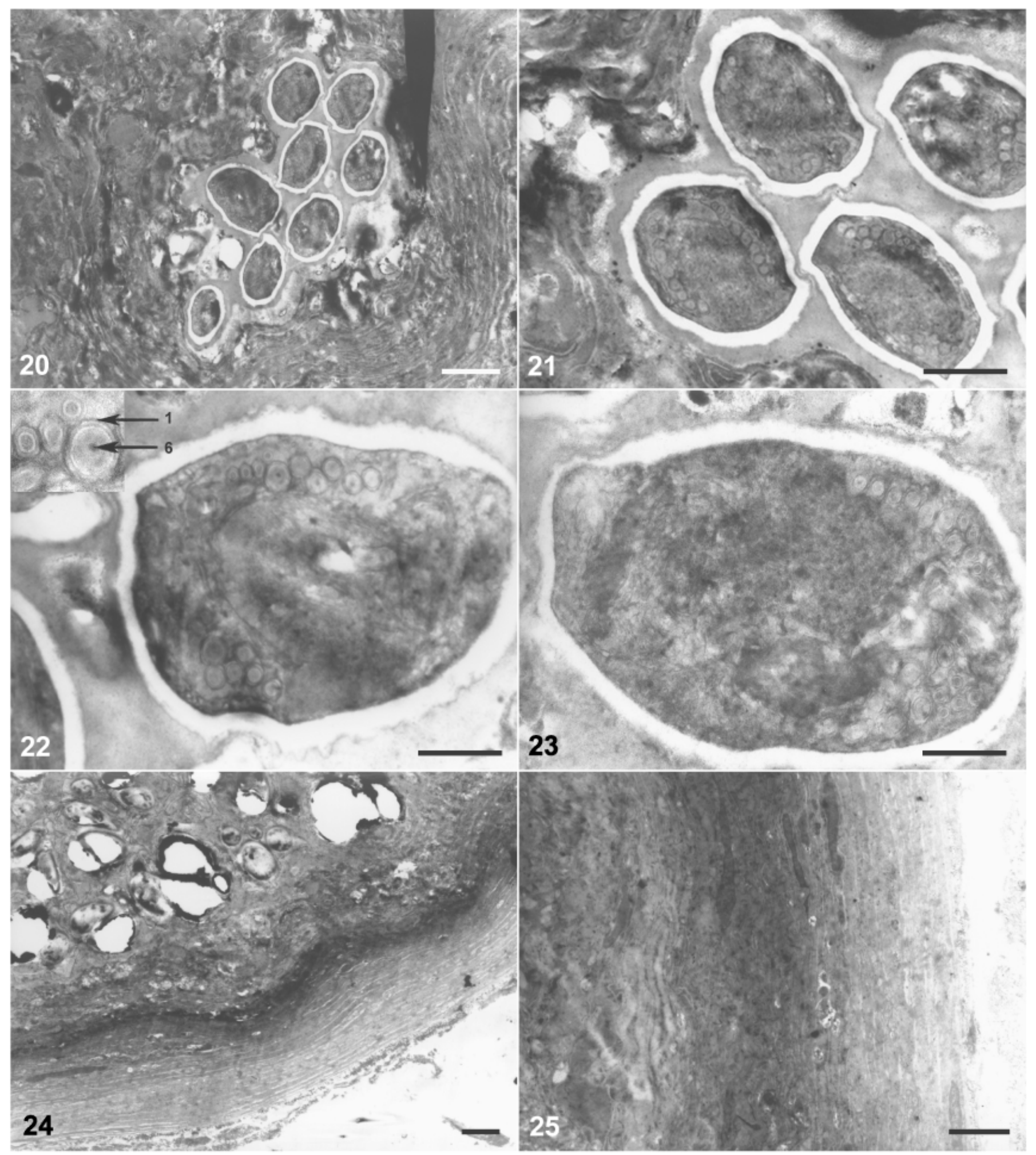

Fig. 20-25. Transmission electron micrographs of Myosporidium merluccius n. g., n. sp. 20. Spores within a sporophorous vesicle. 21. Detail from Fig. 20. 22-23. Mature spores showing the arrangement of the coils is an anisofilar type. The inset shows more clearly the anisofilar filaments composed of six layers. 24-25. Two views of the fibroblast layers surrounding the external part of the filament. (Scale bars: Fig. $20,24,25=2 \mu \mathrm{m}$; Fig. $21=1 \mu \mathrm{m}$; Fig. $22,23=0.5 \mu \mathrm{m}$.) 


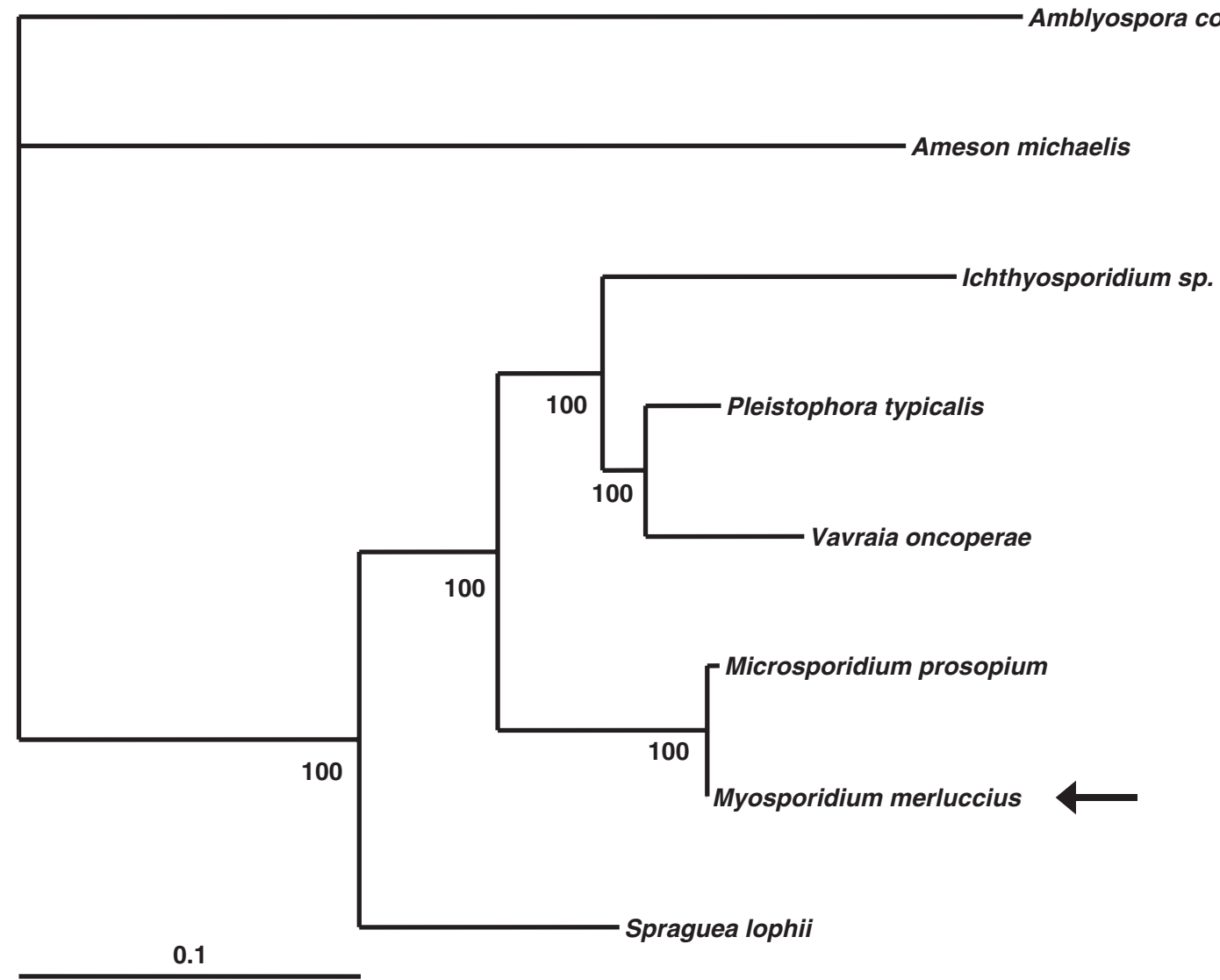

Fig. 26. Phylogenetic tree for the complete 16S rRNA gene of selected Microsporidia from the Ichthyosporidium group as in Kent et al. (1999). The tree was computed by using the quartet puzzling maximum likelihood method of the TREE-PUZZLE program. The scale bar indicates an evolutionary distance of 0.1 nucleotide substitutions per position in the sequence. The tree was oriented by using the 16S rRNA sequence of Amblyospora connecticus as the outgroup.

The length of the aligned sequences used for phylogenetic analysis was 1,381 bases after flush trimming the ends. Before phylogenetic analysis, columns of the alignment that contained gaps and unresolved positions were deleted resulting in an alignment that was 1168 bases long (the alignment is available from the authors upon request). TREE-PUZZLE phylogenetic analysis resulted in a very robust tree with $100 \%$ quartet puzzling support for all branches. The phylogenetic tree, oriented by using Amblyospora connecticus as the outgroup, demonstrates that Microsporidium prosopium and Myosporidium merluccius n. g., n. sp. form a very robust sister group, well separated from other species in the Ichthyosporidium group (Fig. 26).

\section{DISCUSSION}

Xenoma envelope. The wall of the xenoma of Myosporidium merluccius $\mathrm{n}$. g., n. sp. seems to be formed exclusively by the host as a protection against the parasite. This may be the reason why the muscle appeared to be normal, without signs of inflammation or myositis. A possible explanation is that hake is not the principal host for this parasite. It is important to point out that the spores from the xenoma maintained their infective capacity after weeks of storage at $-30{ }^{\circ} \mathrm{C}$, as judged by the polar tube extrusions. As noted by Vávra and Larsson (1999), extrusion of polar filaments may happen under such conditions, albeit rarely.

Two types of xenomas were observed possibly representing different developmental stages of the spores as can be seen in Fig. 16-19. The first type contained dense bodies that were interpreted as developing polar tube coils. The second type of xenoma contained mature spores. We observed that the development from sporont to the mature spore was of the merogony type (i.e. without formation of a multinucleate plasmodium). This pattern of development does not seem to fit into any of the nine patterns of sporogenesis described by Lom and Nilsen (2003).

Spores. Under TEM, the spores had an irregular shape, very similar to many genera of microsporidia (see e.g. Canning 2001; Kent et al. 1999). Spores had a very dense and hard wall, impenetrable to osmium, seen as a white area surrounding the spores, similar to spores of $M$. prosopium in Kent et al. (1999). The polar tubes were of the anisofilar type with six to seven wide coils and five narrow coils in two rows. This feature was distinctive for the new species described here, in contrast to the sister taxon, $M$. prosopium, which has isofilar polar tubes with 12-16 coils in a single row. The internal coil structure matched the description of Vávra and Larsson (1999) for the polar filament structure of six layers for both diameters of the polar tube. Morphologically the spores of these species differ by the number and type of polar tube coils; the size of the spores was different as well: 2.5-3.2 $\times 2.1 \mu \mathrm{m}$ for Myosporidium merluccius $\mathrm{n}$. g., n. sp. and $5-7 \times 3-4 \mu \mathrm{m}$ for $M$. prosopium. The formation of a xenoma and the presence of spororophorous vesicles that were found for Myosporidium merluccius n. g., n. sp. were not observed for $M$. prosopium. Nonetheless, the site of infection in fish muscle is identical for these two species.

Sequence analysis. GenBank BLAST searches have revealed that the sequence of the Myosporidium merluccius n. g., n. sp. 16S 
rRNA gene shows a $99.03 \%$ identity with the $16 \mathrm{~S}$ rRNA sequence of $M$. prosopium. As noted by Lom and Nilsen (2003) for $M$. prosopium, its $16 \mathrm{~S}$ rRNA is very distinct from all other microsporidian 16S rRNA sequences, possibly forming a separate taxonomic group at least at the family level among fish microsporidia. This conclusion is supported by the results of our phylogenetic analysis.

Differences. Although the $16 \mathrm{~S}$ rRNA sequences of these two species are very similar and distinct from other known Microsporidia, these two species display significant morphological differences. Among histological characters examined, only the spore of both species can be compared, and they were different as discussed above. In addition, the host and the geographic distribution are very different: while Myosporidium merluccius n. g., n. sp. has been found in the hake (Merluccius capensis/paradoxus complex) in coastal Namibian fisheries, $M$. prosopium has been found in Prosopium williamsoni (Mountain Whitefish) in fresh waters of Lake Kootenay (British Columbia, Canada).

Fish microsporidia are a difficult group to study due the complexity of their life cycles, morphology, and the variations in their $16 \mathrm{~S}$ rRNA sequence. In addition to 156 recorded species assigned to 14 genera, 13 species were assigned to a collective genus $M i$ crosporidium Balbiani, 1884 (Lom and Nilsen 2003). As noted by these authors, partial morphological observations and judgements in the absence of molecular analysis may result in lumping together into one genus species that are not congeneric. Extending these taxonomic criteria to higher order taxa, Lom and Nilsen (2003) proposed to divide fish Microsporidia into five groups naming some of them families, while other groups were named as clades, leaving $M$. prosopium outside these groups. When molecular information for more fish microsporidia are available, it may be practical to create a new family to include the new species described herein and Microsporidium prosopium.

Filaments found in the hake fillets sent to our laboratory were similar in color and in size to the Kudoa sp. (Myxosporea) cysts, frequently observed in hake muscle. Our study unambiguously demonstrated that the filaments we have described were due to an infection with microsporidia, even though these xenomas were found to be different from cysts or xenomas of other fish microsporidia (Glugea, Loma, Ichthyosporidium, Spraguea, Tetramicra, and Microgemma). In fact, using the key of Lom (2002), morphological classification of this new species cannot be continued beyond the third step of the key. Using other morphological characters than those used by Lom (2002) (e.g. the type of the polar coil, the type of merogonic and sporogonic development), Myosporidium merluccius n. g., n. sp. may be grouped together with Trachipleistophora, because these two genera share the presence of sporophorous vesicles and of anisofilar coils in the spore (Trachipleistophora has 8-11 wide and 2-3 narrow coils); on the other hand, Trachipleistophora does not form xenoma.

Following all these considerations and because phylogenetic analysis clearly separated this new species from other species of fish Microsporidia grouped in clades or families, we think that it is a new genus that together with $M$. prosopium may be classified to a new clade or family. The question whether this new species and $M$. prosopium are congeneric is very difficult to answer because they show striking morphological differences while being $99.03 \%$ identical in their $16 \mathrm{~S}$ rRNA sequences.

\section{Taxonomic Summary \\ Phylum Microsporidia Balbiani 1882 \\ Class Haplophasea Sprague, Becnel and Hazard 1992 Order Glugeida Issi, 1986}

Myosporidium n. g. The development from sporont to the mature spore is of the merogony type without formation of a multinucleate plasmodium. The spores are monokaryotic and are included within sporophorous vesicles. Each sporophorous vesicle has 30-50 spores. Anisofilar polar tube. Live spores are pyriform under light microscopy, and after processing for TEM exhibit a oval and irregular shape. There is a thick endospore wall. It forms a xenoma. The generic name (Myosporidium) denotes the tissue infected: myos (from greek myôn: muscle) and spora (from greek sporà: semen). The gender is masculine. Type species: Myosporidium merluccius n. sp.

Myosporidium merluccius n. sp. The features of the genus, that is monospecific, are not mentioned again. Spores mononucleated $2.5-3.3 \mu \mathrm{m}$ in length $\times 1.76-2.1 \mu \mathrm{m}$ in width. The anisofilar polar tube has $11-12$ coils (6-7 wide and 5 narrow). The sporophorous vesicles are within a dark xenoma, surrounded by fibroblasts. The xenomas are located inserted among muscle fibers. The type host is Merluccius capensis/paradoxus complex. The species name is based on the generic name of the species host (Merluccius) in apposition (nominative). The gender is masculine. Type locality: fisheries in Namibian waters.

Type material. Hapantotypes in histological sections (20 slides), a block of paraffin, 10 inclusions in Epon for TEM, and infested tissue in formalin have been deposited in the Museum of Zoology, University of Navarra, Spain, as catalogue number MZNA-H-029.

16S rRNA sequence. GenBank Accession number AY530532.

The relative proximity in phylogenetic grouping of this new species with microsporidial species infecting humans (Pleistophora and Trachipleistophora) and the presence in the hake (a widely consumed human food) may be of importance as a possible emerging disease (Slifko, Smith, and Rose 2000) at least in immunodeficient persons.

\section{ACKNOWLEDGMENTS}

We would like to thank Dr. Elizabeth U. Canning (Imperial College of Science, Technology and Medicine, London, UK) for her encouragement and helpful suggestions. Blanca Irigoyen and Laura Guembe (Department of Histology and Pathological Anatomy, University of Navarra) prepared the material for TEM. Dr. Miguel A. Idoate (University Hospital, University of Navarra, Pamplona) assisted us with the interpretation of histology observations. We would also like to thank Dr. Govinda S. Visvesvara for the review of the manuscript.

\section{LITERATURE CITED}

Canning, E. U. 2001. Microsporidia. In: Gillespie, S. \& Pearson, R. D. (ed.), Principles and Practice of Clinical Parasitology. John Wiley \& Son Ltd., Chichester, UK. p. 171-195.

Canning, E. U. \& Lom, J. 1986. The Microsporidia of Vertebrates. Academic Press, London, UK. 289 p.

Da Silva, A. J., Bornay-Llinares, F. J., Moura, I. N. S., Slemenda, S. B., Tuttle, J. L. \& Pieniazek, N. J. 1999. Fast and reliable extraction of protozoan parasite DNA from fecal specimens. Mol. Diag., 4:57-64.

Dyková, I. 1995. Phylum Microspora. In: Woo, P. T. K. (ed.), Fish Diseases and Disorders. Vol. 1. CAB International, Wallinford, UK. p. 149-179.

Kent, M. L., Docker, M., Khattra, J., Vossbrink, C. R., Speare, D. J. \& Devlin, R. H. 1999. A new Microsporidium sp. (Microsporidia) from the musculature of the mountain white fish Prosopium williamsoni from British Columbia: morphology and phylogeny. J. Parasitol., 85: 1114-1119.

Lom, J. 2002. A catalogue of described genera and species of microsporidians parasitic in fish. Syst. Parasitol., 53:81-99.

Lom, J. \& Dyková, I. 1992. Developments in Aquaculture and Fisheries Science, Vol. 26. Protozoan Parasites of Fishes. Elsevier Science Publishers B. V., Amsterdam. 315 p.

Lom, J. \& Nilsen, F. 2003. Fish microsporidia: fine structural diversity and phylogeny. Int. J. Parasitol., 33:107-127. 
Page, R. D. M. 1996. TreeView: an application to display phylogenetic trees on personal computers. Comput. Appl. Biosci., 12:357-358.

Shaw, R. W. \& Kent, M. L. 1999. Fish microsporidia. In: Wittner, M. \& Weiss, L. M. (ed.), The Microsporidia and Microsporidiosis. American Society for Microbiology, Washington, DC. p. 418-446.

Slifko, T. R., Smith, H. V. \& Rose, J. B. 2000. Emerging parasite zoonoses associated with water and food. Int. J. Parasitol., 30:1379-1393.

Strimmer, K. \& von Haeseler, A. 1996. Quartet puzzling: a quartet maximum-likelihood method for reconstructing tree topologies. Mol. Biol. Evol., 13:964-969.
Thompson, J. D., Higgins, D. G. \& Gibson, T. J. 1994. CLUSTAL W: improving the sensitivity of progressive multiple sequence alignment through sequence weighting, position-specific gap penalties and weight matrix choice. Nucleic Acids Res., 22:4673-4680.

Vávra, J. \& Larsson, J. I. 1999. Structure of the Microsporidia. In: Wittner, M. \& Weiss, L. M. (ed.), The Microsporidia and Microsporidiosis. American Society for Microbiology, Washington, DC. p. 7-84.

Received: 08/4/04; accepted: 05/25/05 